OPEN ACCESS

Edited by:

Céline Cruciani-Guglielmacci, Paris Diderot University, France

Reviewed by: Yasser Mohamed El-Wazir, Suez Canal University, Egypt Isabelle Caillé,

Centre National de la Recherche Scientifique, France

*Correspondence: Sandrine Thure sandrine.1.thuret@kcl.ac.uk

Specialty section

This article was submitted to Integrative Physiology, a section of the journal Frontiers in Physiology

Received: 01 November 2016 Accepted: 09 January 2017 Published: 30 January 2017

Citation: de Lucia C, Murphy T and Thuret S (2017) Emerging Molecular Pathways Governing Dietary Regulation of Neural Stem Cells during Aging. Front. Physiol. 8:17. doi: 10.3389/fphys.2017.00017

\section{Emerging Molecular Pathways Governing Dietary Regulation of Neural Stem Cells during Aging}

\author{
Chiara de Lucia, Tytus Murphy and Sandrine Thuret *
}

Neurogenesis and Mental Health Laboratory, Department of Basic and Clinical Neuroscience, Institute of Psychiatry, Psychology and Neuroscience, King's College London, London, UK

Aging alters cellular and molecular processes, including those of stem cells biology. In particular, changes in neural stem cells (NSCs) are linked to cognitive decline associated with aging. Recently, the systemic environment has been shown to alter both NSCs regulation and age-related cognitive decline. Interestingly, a well-documented and naturally occurring way of altering the composition of the systemic environment is through diet and nutrition. Furthermore, it is well established that the presence of specific nutrients as well as the overall increase or reduction of calorie intake can modulate conserved molecular pathways and respectively reduce or increase lifespan. In this review, we examine these pathways in relation to their function on NSCs and cognitive aging. We highlight the importance of the Sirtuin, mTOR and Insulin/Insulin like growth factor-1 pathways as well as the significant role played by epigenetics in the dietary regulation of NSCs and the need for further research to exploit nutrition as a mode of intervention to regulate NSCs aging.

Keywords: nutrients, diet, aging, mTOR, sirtuins, insulin-like growth factor signaling, IIS, epigenetics

\section{AGING AND NEURAL STEM CELL FUNCTION}

Aging is the number one risk factor for the majority of diseases currently affecting the developed and developing world (Niccoli and Partridge, 2012). The area of study addressing this issue, known as biogerontology, is committed to investigating the underlying mechanisms of aging, to explore whether they can be intervened upon to delay or perhaps even halt the progression of age-related conditions such as cardiovascular disease, cancer and neurodegeneration (Verburgh, 2015). An improved understanding of aging mechanisms could lead to the development of strategies to increase "healthspan"- the period of time free from debilitating disease (Franklin and Tate, 2008; Brandhorst et al., 2015). Aging is linked to a number of cellular and molecular processes including nutrient-sensing pathway, epigenetic and stem cells biology deregulation (López-Otín et al., 2013). Stem cells in general have been closely linked to aging owing to their reduced regenerative ability linked to the decline of tissues that accompanies age (Signer and Morrison, 2013; Behrens et al., 2014). Impaired function of satellite stem cells in muscle and epidermal stem cells of the skin, for example, is a key process underlying reduced regeneration during aging in these tissues (Castilho et al., 2009; Day et al., 2010).

The adult NSC population is also negatively affected by age. Post-natal NSCs, able to differentiate into neurons, have been identified in several areas of the mammalian central nervous system (CNS), including the rodent and human dentate gyrus (DG) of the hippocampus 
and the mouse subventricular zone (SVZ). Postnatal-born neurons-a phenomenon known as adult neurogenesis-in these areas have been implicated in learning and memory and olfaction respectively (Altman and Das, 1965; Pencea et al., 2001; Spalding et al., 2013). More recently post-natal NSC-derived neurons have also been identified in the mouse hypothalamus and the human striatum (Kokoeva et al., 2005; Ernst et al., 2014). Though mouse models have been extensively used in adult neurogenesis research, it is becoming clear that there are considerable differences between rodent and human neurogenesis: firstly, there seems to be no neuron turnover in the human olfactory bulb, whilst this is an important neurogenic zone in the mouse brain. Secondly, whilst hippocampal neurogenesis occurs in both species, retrospective birth dating of human postmortem tissue has revealed that nearly all of the dentate granule "turnover" during adult life, whereas only $10 \%$ of the mouse granule neurons are exchanged in adulthood (Spalding et al., 2013). Furthermore, the rate of decline in hippocampal neurogenesis in response to age appears far greater in mice than in humans (Bergmann et al., 2015).

The marked decline in NSC activity in the aging rodent DG manifests in reduced proliferation that eventually leads to the depletion of the progenitor pool (Romine et al., 2015; Yang et al., 2015). This decline partly contributes to the age-linked decline in cognitive abilities, particularly those dependent on the hippocampus (Park et al., 2013; Romine et al., 2015; Yang et al., 2015). In the SVZ, there is a similar marked decline in NSC function and this contributes to impoverished olfaction during rodent aging (Enwere et al., 2004). Studies in model species have shown that deregulated hippocampal neurogenesis, is an important component of neurodegenerative conditions such as Alzheimer's (López-Toledano and Shelanski, 2004, 2007; Winner et al., 2011), further linking declines in NSC function to the deterioration of the aging brain. Aging therefore appears to exert some of its detrimental effects in the CNS by directly interfering with multiple cellular and molecular processes that govern the regulation of the NSC population. This notion is summarized in Figure 1. As aging has such severe effects on the decline of NSC and the development of neurodegenerative conditions, this prompts the field to consider whether we can we target the maintenance of the NSC population to slow cognitive aging and neurodegenerative disease progression? If so, what are the key mechanisms to target?

Interestingly, studies investigating the role of aging on NSCs have also highlighted the importance of the systemic milieu in regulating the neurogenic niches of the CNS; through the use of heterochronic parabiosis, Villeda and colleagues showed that the systemic environment of a young mouse was able to rescue the cognitive deficits of an aged mouse following the fusion of young-old circulatory systems (Villeda et al., 2011, 2014). This rejuvenating effect is also observed following intravenous infusion of young plasma into old mice, and was underpinned by a marked reversal of age-related decline in hippocampal neurogenesis (Villeda et al., 2011) and upregulation of genes linked to synaptic plasticity (Villeda et al., 2014). Similarly, enhanced neurogenesis in the SVZ was observed by Katsimpardi and colleagues following heterochronic parabiosis,

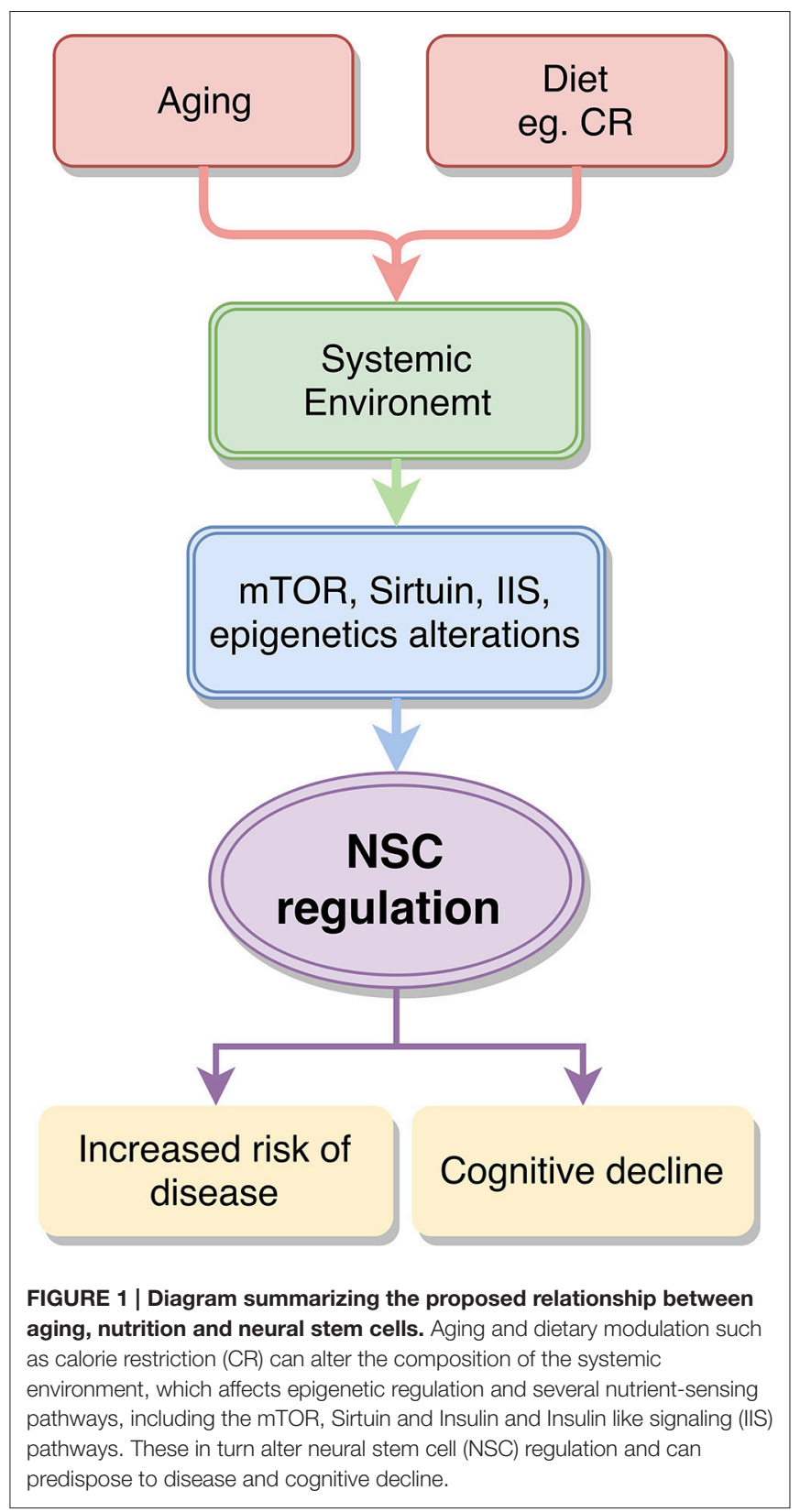

resulting in improved odor discrimination (Katsimpardi et al., 2014). Notably, these studies have demonstrated the role for candidate chemokines (e.g., CCL11, Villeda et al., 2011) and growth factors (e.g., GDF11 e.g., Loffredo et al., 2013) whose circulating levels fluctuate in aging mice and appear to exert their effects, at least in part, by altering NSC function. Complementary to this, studies looking at other populations of stem cells have observed a similarly rejuvenating effect of the youthful milieu on the typical age-related declines in stem cell function throughout the body as well as vice-versa, whereby the old milieu inhibited stem cell function (Conboy and Rando, 2012). These data suggest that by altering the composition of the systemic environment, one could affect the regulation of the NSCs; a well-documented, naturally occurring way of achieving 
this is through diet and nutrition (Stangl and Thuret, 2009). We define diet as encompassing dietary paradigms such as calorie restriction (CR), intermitted fasting (IF), dietary restriction (e.g., of specific components such as protein) (DR) and time restricted feeding (TRF) whereas nutrition involves the intake and/or supplementation of foods containing pro-neurogenic agents such as polyphenols, polyunsaturated fatty acids (PUFAs) and vitamins/minerals.

As stem cells in general are designed to act in response to their environment and, and as reported above, are responsive to differing compositions of the systemic environment, it follows that diet can greatly influence their function (Murphy and Thuret, 2015). Several authors have reviewed the effect of diet on stem cells in general (Rafalski et al., 2012; Ochocki and Simon, 2013; Mihaylova et al., 2014), for the purpose of this review we will focus on the relatively unexplored field of the effects of diet and aging on NSCs. Briefly, nutritionists have found that an overabundance of nutrients is detrimental to several aspects of human and animal health (Keenan et al., 1994; Nagai et al., 2012). This results from an overstimulation of nutrient sensing molecular pathways, which eventually become insensitive to the stimuli (Blagosklonny, 2008; Gems and de la Guardia, 2013). CR, IF and DR have been reported to have opposite effects on these pathways and present a means to improved health and life span (Solon-Biet et al., 2014, 2015; Brandhorst et al., 2015; Fontana and Partridge, 2015). Figure 1 is a schematic of how aging, diet and the systemic environment interact to act upon these pathways. Notably, these effects are conserved across species as they have been observed in simple organisms such as yeast, C. elegans, and drosophila through to rodents and humans (Fontana et al., 2010). We now review the impacts of dietary and nutritional regulation of NSC activity and function, with focus on the aforementioned nutrient sensing pathways and their effects on longevity.

\section{IMPACT OF DIET ON NEURAL STEM CELLS}

Dietary paradigms such as CR and IF are the most widely employed means of assessing the impacts of diet upon stem cell function and longevity. A $30-40 \%$ reduction in calorie intake, the typical regimen for $\mathrm{CR}$, has often been brought about by alternate-day feeding - a form of IF. As such, the field must pay great attention as to whether they are assessing the impacts of DR or IF, unpublished work from our lab shows that the positive impacts of IF on hippocampal neurogenesis and cognitive performance can be derived independent of calorie intake, suggesting that it is the period of fasting that that is acting on the NSC pool. Nutritional content, such as the amount of polyphenols and PUFAs, among other specific nutrients, has also been reported to impact on NSC function during aging (see Maruszak et al., 2014; Murphy and Thuret, 2015 for review).

Reducing calorie intake in rodents was shown to counteract age-related cognitive decline as well as increase the number of newly generated neurons in the hippocampus (Ingram et al., 1987; Lee et al., 2000, 2002). Furthermore, Kumar and colleagues suggest DR may aid in fighting excitotoxic injury as an increase in progenitors is seen in the SVZ, SGL, hypothalamus and cortex of adult rats (Kumar et al., 2009). In contrast, Bondolfi and colleagues found that CR did not affect the rate of neurogenesis but affected the survival of new-born glia in the mouse hippocampus (Bondolfi et al., 2004). Given that $\mathrm{CR}$ and IF (typically involving some degree of CR) have been shown to positively impact on NSC function, it follows that excessive calorie intake, as in the case of obesity and other models of metabolic disorders, will negatively affect NSC activity and may decrease adult hippocampal neurogenesis (Stangl and Thuret, 2009). Furthermore, obesity was a detrimental factor in studies investigating post-stroke recovery in humans, suggesting that a history of increased calorie intake impairs brain repair (Kalichman et al., 2007). Interestingly, CR was also proven beneficial in elderly humans as shown by improved verbal memory scores (Witte et al., 2009). It must be considered however, that in elderly, sometimes frail individuals, restricting of calories may be too dangerous, older populations may therefore benefit from more targeted pharmacological interventions to modulate NSCs activity based on CR/IF and DR mimetics.

Though it may seem counter intuitive that reducing calories may be beneficial to stem cells in particular, this can be explained by our historical food supply not being readily available and abundant at all times. Humans have evolved to cope with periods of reduced calorie intake, resembling the effect achieved by CR and IF experiments. A possible biological explanation for this relies on the benefits of refeeding after a fasting period, suggesting that when an organism is "fasting" it can focus on preparing resources to act quickly and effectively when nutrients do become available (Reed et al., 1996). With respects to the NSCs of the DG in particular, their activity is possibly enhanced in the absence of nutrients owing to the necessity of "hunting behavior" and the requirement for cognitive flexibility that must accompany it: improved cognition may be a means to ensure food is found (As discussed by Mattson, 2012).

\section{SUPPORTING EVIDENCE FOR THE ROLE OF NUTRIENT-SENSING PATHWAYS IN NEURAL STEM CELL REGULATION AND LONGEVITY}

Owing to the compelling research relating diet to longevity and to NSCs, the field is now trying to delineate the molecular pathways behind this relationship. Though many pathways are involved in NSC regulation and an equally vast amount is involved in nutrient-sensing and aging, there is a relatively small proportion identified as relating the three. Thus far, the best characterized, and therefore most promising starting point for imminent studies, are the mTOR, Insulin and Insulin-like growth factor signaling and Sirtuin pathways. In this section, we will focus on the available data supporting a role for these pathways in aging, nutrient sensing and NSC regulation. See Figure 2 for a summary of key NSC related functions affected by these pathways. 


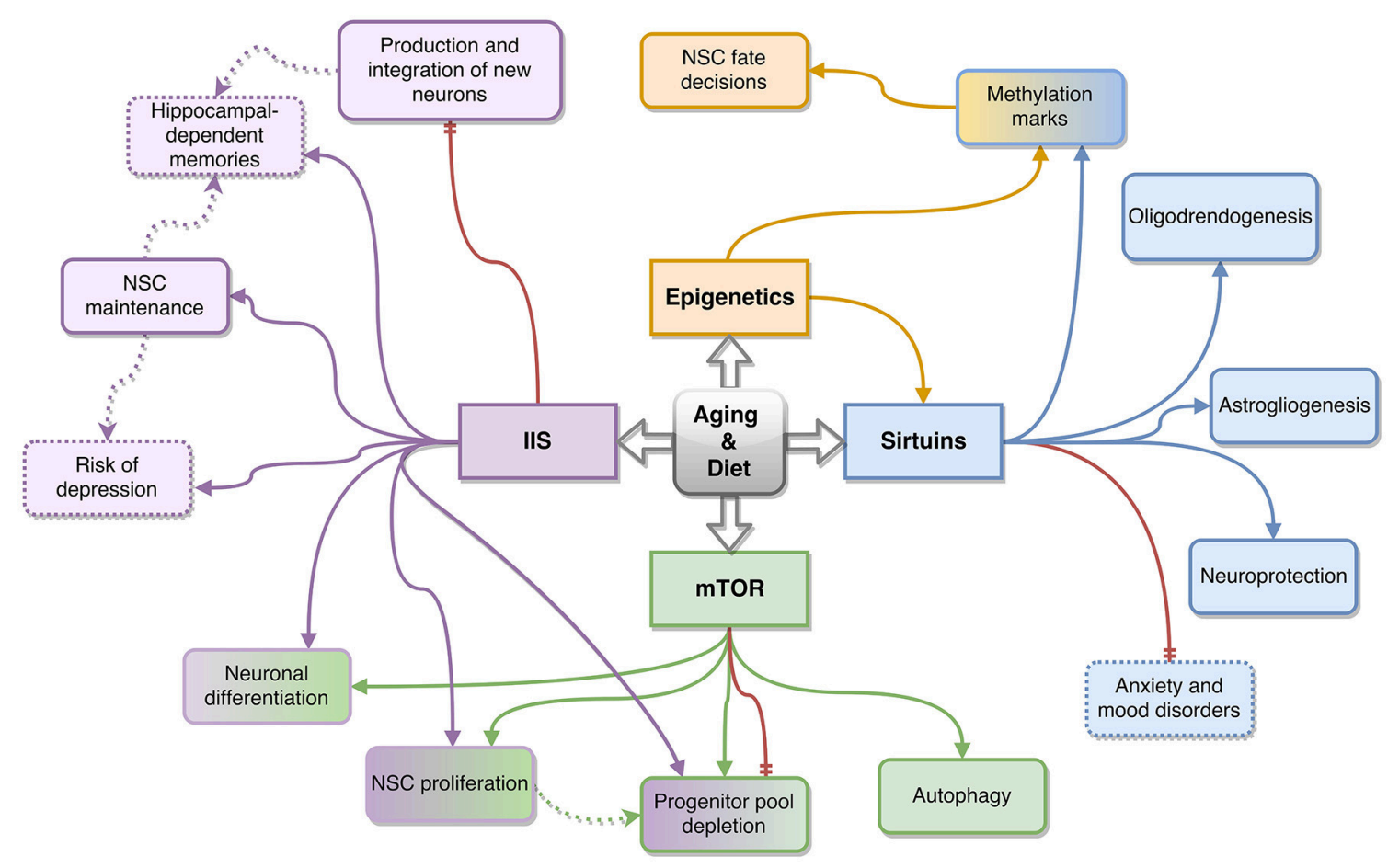

FIGURE 2 | Schematic summarizing the key effects of the Insulin/Insulin-like Growth factor (IIS) (in purple), mTOR (in green), sirtuin (in blue) and epigenetic (in orange) pathways on neural stem cell (NSC) function as a result of diet and aging. Solid arrows represent relationships between the molecular pathways (represented by the four rectangles in the center) and NSC function (represented by the outer, rounded rectangles) or related phenotypes (dotted rounded rectangles) discussed in this review. The dotted arrows connect possible molecular mechanisms behind the observed phenotypes reported in this review. Red arrows represent an effect caused by the inhibition of the pathway they stem from. Boxes with gradient coloring represent functions affected by multiple pathways.

\section{mTOR}

The mammalian target of rapamycin (mTOR) is a classical dietary and nutrient sensing pathway. mTOR is a serine/threonine kinase. It combines with several accessory proteins including RAPTOR or RICTOR to form mTOR complex 1 (mTORC1) and mTOR complex 2 (mTORC2), respectively. The two complexes carry out different functions with mTORC1 being responsible for cell growth and metabolism while mTORC2 regulates cytoskeleton organization. Importantly, mTOR is the catalytic subunit of the complex and is inhibited by the presence of rapamycin, this inhibition however only occurs when mTOR is bound to the RAPTOR protein (Magri and Galli, 2013). mTOR activity is altered by energy and amino acid availability as well as growth factors, making it a key molecule within nutrition studies (Magri and Galli, 2013). mTOR is also involved in a feedback loop with insulin where insulin (discussed below) activates mTOR and mTOR phosphorylates the S6 kinase, which in turn inhibits insulin signaling (Blagosklonny, 2008). In the liver, branched chain amino acids (BCAA) in particular signal for mTOR activation, showing that protein intake and specific amino acids alter the total activation of mTOR (measured as phosphorylated mTOR / total mTOR) and ultimately longevity (Solon-Biet et al., 2014).

As well as functions in nutrient sensing, the mTOR pathway has also been linked to longevity (Blagosklonny, 2010). Its inhibition via ethylaxanthine and rapamycin was shown to improve longevity in yeast (Wanke et al., 2008) and mice (Harrison et al., 2009; Fok et al., 2014) respectively, leading to plans to test the compound in larger and longer-lived mammals such as companion dogs (Check Hayden, 2014). Recently, the mechanism of action behind rapamycin's role in longevity was suggested to involve a decrease in reactive oxygen species, as shown by experiments in the rodent liver (Martínez-Cisuelo et al., 2016). Notably, rapamycin treatment was shown to exert its beneficial effects even if started at advanced age, a factor, which usually greatly impairs the efficacy of lifeextending interventions (Harrison et al., 2009). In addition, Tan and colleagues highlighted increased PI3K/Akt/mTOR pathway activation during aging as the molecular mechanism responsible for replicative senescence in vascular smooth muscle cells (Tan et al., 2016). This pathway has been the focus of aging research and is shared by both the mTOR and the insulin-like growth factor signaling (IIS) pathways as explained in Section Insulin. Several consequences of mTOR activation increase the risk of premature aging and disease, these include decreased autophagy accompanied by an increase in protein production eventually causing an increase in protein agglomeration as well as an increase in inflammation (Verburgh, 2015). Furthermore, chronic mTOR activation causes increased proliferation of several types of stem cells eventually leading to progenitor pool 
depletion. Adequate mTOR regulation could thus be key in maintaining these populations throughout aging (Sato et al., 2010; Paliouras et al., 2012).

Though there is a limited number of studies investigating the role of mTOR within the NSC population, there have been several encouraging findings supporting key functions for this nutrient sensing pathway in NSC regulation and aging.

Firstly, both protein deposition and inflammation are key hallmarks of neurodegenerative conditions suggesting that mTOR hyperactivity may contribute to disease progression within the CNS (O’ Neill, 2013). These observations are consistent with the evidence supporting aging as a consequence of overstimulation of signaling pathways, driven by the overabundance of nutrients. Furthermore, mTOR has also been shown to be key in dictating the proliferation rate of the adult SVZ NSC population; its inhibition in fact, caused progenitor pool depletion (Paliouras et al., 2012). In addition, Han and colleagues have also reported that, during embryonic development, mTOR carries an important role for neuronal differentiation: enhancing mTOR activity via insulin caused an increase in the number of neurons, which was counteracted by rapamycin. Intriguingly, in the presence of rapamycin the decrease in neuronal numbers was attributed to increased autophagy rather than apoptosis (Han et al., 2008). These findings also suggested the possibility of similar mechanisms taking place in adult NSCs. Indeed, $\mathrm{Yu}$ and colleagues showed that increased autophagic death also occurred in adult hippocampal NSC following insulin withdrawal and was accompanied by a decrease in cell density, these effects were also exacerbated by the presence of rapamycin, implicating mTOR activity (Yu et al., 2008). The authors state that in an aged environment there is decreased insulin signaling and thus increased autophagy, which may reduce the survival of stem cells. Contrary to this, the authors remark that autophagy can enhance cell survival, given its beneficial effect in clearing unwanted and malfunctioning cells, an essential mechanism in the context of aging (Cuervo, 2008). Elevated autophagy in response to reduced insulin signaling may thus not be a solely negative effect but further research is required to better delineate the modulatory role of mTOR activity in NSC during aging (Gems and de la Guardia, 2013).

The limited number of studies (See Table 1) however, highlights the need for further investigations into the exact mechanisms of mTOR regulation in adult NSCs, with the ultimate aim of determining whether modulation of this pathway can bring preserve the NSC pool during aging. The key effects of the mTOR pathway on NSCs elucidated this far are depicted in Figure 2.

\section{Insulin}

Insulin and Insulin-like growth factor (IGF) are two hormones closely linked to nutrition, as they respond to increased glucose. Insulin is released by the $\beta$ cells of the pancreas and acts upon transmembrane tyrosine kinase receptor to activate downstream signaling pathways and cause glucose uptake by liver and muscle cells (van Heemst, 2010). Other members of the IGF family are under the control of growth hormone $(\mathrm{GH})$ release by the pituitary gland. They also act upon tyrosine kinase receptors and activate downstream pathways that are often shared with insulin, coining the term insulin/insulin-like growth factor signaling (IIS) pathway. Stimulation of the IIS pathway results in the activation of the PI3K/Akt pathway, a pathway shared with mTOR signaling, which ultimately leads to the inactivation of the FoxO transcription factors (van Heemst, 2010). While both insulin and IGF respond to carbohydrate presence, they usually carry out slightly different roles with insulin being primarily occupied with glucose metabolism and IGF with growth and survival (Rafalski and Brunet, 2011). Besides being activated by carbohydrates such as glucose, the IIS pathway is also stimulated by proteins and is involved in a feedback loop with mTOR as described in Section mTOR (Blagosklonny, 2008).

IIS is also extensively implicated in longevity (Kimura et al., 1997; Bartke et al., 2013); overactivation, like for mTOR, leads to decreases autophagy and ultimately to the shortening of lifespan (Verburgh, 2015). The decrease of the IIS pathway in C. elegans by Kimura and colleagues was one of the first experiments to show an increase in lifespan relating to diminished insulin signaling (Kimura et al., 1997). This was confirmed by several other studies, with Blüher and colleagues showing that the knockout of a fat specific insulin receptor resulted in an increase in lifespan of 18\% (Blüher et al., 2003) and Taguchi et al finding that the knock-out of downstream substrates of the IIS pathway caused a $32 \%$ increase in female mice lifespan (Taguchi et al., 2007). Furthermore, serum IGF-1 levels in 31 different mouse strains negatively correlated to average lifespan (Yuan et al., 2009). Some encouraging evidence has also been found relating IIS to human longevity; IIS related polymorphisms correlate to lifespan (Bonafè et al., 2003; Kojima et al., 2004) and several centenarians were found to have loss of function mutations in the IGF-1 receptors (Suh et al., 2008). Conversely, people affected by acromegaly, characterized by increased GH release, experienced a 2-3 fold increase in death rate (Clayton, 2003; Suh et al., 2008; Verburgh, 2015). More recently, reduced growth hormone secretion, and thus indirectly IIS activity, was shown to correlate with human familial longevity (van der Spoel et al., 2016) and genomewide meta-analysis studies linked several gene loci to longevity and to levels of circulating IGF-related proteins (Teumer et al., 2016). These studies show that this pathway and its role in lifespan is conserved in more complex organisms.

Several rodent studies have suggested insulin and IGF may link nutrition to organism longevity through key functions in tissue-specific stem cell maintenance. Mechanisms such as autophagy, compromised by IIS overstimulation, carry out key functions within the stem cell population. FoxO3A was proven essential for efficient clearing of age-related cellular debris which is known to prevent malfunctioning of stem cells and to lead to improved longevity (Cuervo, 2008; Warr et al., 2013). The IIS pathway also appears to have important functions on the regulation of neural stem cells specifically, with studies implicating it in both development and adulthood.

IGF-1 overexpression alone and IGF-1 and insulin overexpression on embryonic NSC for example, highlighted that insulin pushes toward increased differentiation while IGF-1 pushes toward a proliferative phenotype (Arsenijevic et al., 2001). Furthermore, studies have shown that overexpression of 
TABLE 1 | Table summarizing studies showing supporting evidence for the role of mTOR, IIS, and Sirtuin pathways in NSCs function.

\begin{tabular}{|c|c|c|c|c|c|}
\hline Pathway & Model & NSC & Intervention & Supporting evidence & Study \\
\hline mTOR/IIS & Rat In vitro & Embryonic & Increased insulin levels & $\begin{array}{l}\text { Increase in differentiated neurons, which was } \\
\text { counteracted by rapamycin }\end{array}$ & Han et al., 2008 \\
\hline mTOR/IIS & Rat In vitro & DG & Insulin withdrawal & $\begin{array}{l}\text { Increased neuronal death, exacerbated by } \\
\text { rapamycin }\end{array}$ & Yu et al., 2008 \\
\hline IIS & Mouse In vitro & SVZ and DG & FoxO3 knockout & $\begin{array}{l}\text { Decreased number of NSC and self-renewal } \\
\text { ability }\end{array}$ & Renault et al., 2009 \\
\hline mTOR/IIS & Rat In vivo & Cortex & Treated with EGCG + TBI & Reduced NSC cell death around damaged area & Itoh et al., 2012 \\
\hline IIS & Rat In vitro & DG & Increased IGF-1 & $\begin{array}{l}\text { Decreased differentiation and increased } \\
\text { proliferation of NSCs }\end{array}$ & Åberg et al., 2003 \\
\hline IIS & Mouse In vitro & Striatal & Increased insulin & Increases NSCs differentiation & Arsenijevic et al., 2001 \\
\hline IIS & Mouse In vivo & Perinatal & IGF-1 overexpression & $\begin{array}{l}\text { Increase in number of neurons and of } \\
\text { oligodendrocytes. }\end{array}$ & Carson et al., 1993 \\
\hline IIS & Mouse In vivo & Perinatal & IGF-1 KO & $\begin{array}{l}\text { Decreased proliferation and differentiation of } \\
\text { oligodendrocytes }\end{array}$ & Ye et al., 2002 \\
\hline IGF-1 & Mouse In vivo & SVZ & IGF-1R KO & Reduced age related depletion of NSC & Chaker et al., 2015 \\
\hline IGF-II & Mouse In vitro & Perinatal & |GF-I| treatment & $\begin{array}{l}\text { Increased NSC expansion and promoted } \\
\text { self-renewal }\end{array}$ & Ziegler et al., 2012 \\
\hline IGF-II & Mouse In vitro & DG & Sh-RNA knockdown of /GF-II & Impaired proliferation & Bracko et al., 2012 \\
\hline Sirtuins & Mouse In vitro & Perinatal SVZ & Oxidation or Sirt1 activation & Enhanced astrocytic lineage & Prozorovski et al., 2008 \\
\hline Sirtuins & Mouse In vitro & Perinatal SVZ & Reducing environment & Enhanced neuronal lineage & Prozorovski et al., 2008 \\
\hline Sirtuins & Mouse In vitro & Perinatal SVZ & Sh-RNA knockdown of Sirt1 & Disengaged neural fate from redox conditions & Prozorovski et al., 2008 \\
\hline Sirtuins & Mouse In vivo & SVZ and DG & Inactivation of Sirt1 & $\begin{array}{l}\text { Increased oligodendrocyte differentiation and } \\
\text { myelination }\end{array}$ & Rafalski et al., 2013 \\
\hline Sirtuins/NAMPT & Mouse In vivo & DG & Measuring /ablating NAMPT & $\begin{array}{l}\text { NAMPT levels decrease with age, its ablation } \\
\text { reduces NSC proliferation and } \\
\text { oligodendrogenesis }\end{array}$ & Stein and Imai, 2014 \\
\hline Epigenetics & Mouse In vitro & Embryonic & Dnmt1 knockout & Increased astrocytic differentiation & Fan et al., 2005 \\
\hline Epigenetics & Mouse In vitro & Perinatal SVZ & Dnmt3 knockout & Impaired neuronal differentiation & Wu et al., 2010 \\
\hline
\end{tabular}

NSC, neural stem cells, IIS, insulin and insulin-like signaling, DG, dentate gyrus, SVZ, sub ventricular zone, KO, knockout.

IGF-1 leads to increased brain size due to increased myelination (Carson et al., 1993). Finally, Igf-1 null mice presented with decreased proliferation and differentiation of oligodendrocyte lineage (Ye et al., 2002).

Whether these effects persist into adulthood requires further investigation. Recently however, Chaker and colleagues showed that the inhibition of IGF-1 signaling in rodent adult olfactory bulb NSCs was able to hinder age-related stem cell decline and preserve the production and integration of newborn neurons (Chaker et al., 2015). IGF-1 was also shown to stimulate proliferation of adult hippocampal NSC both in vivo and in vitro while blocking the PI3K/Akt pathway stopped the proliferative effects of IGF-1 on NSCs (Åberg et al., 2000, 2003). This was later supported by Chigogora and colleagues finding a correlation between IGF-1 levels and an elevated risk of human depression (Chigogora et al., 2016), a disorder known to involve neurogenic and possible NSC deregulation (Hill et al., 2015). Furthermore, the deletion of the FoxO family members results in increased brain size and proliferation during development but also in a depletion of the progenitor pool and ultimately a decrease of SVZ adult neurogenesis (Paik et al., 2009; Renault et al., 2009). FoxO3 in particular seems to regulate quiescence of the adult SGL and SVZ NSC population and to have a role in oligodendrocyte regulation. FoxO transcription factors are also sensitive to oxygen changes making them ideal effectors between oxidative stress, a known aspect of aging, and stem cell maintenance (Renault et al., 2009). Besides these studies, several others have reported pro-neurogenic effects of insulin when investigating the mTOR pathway as discussed in Section mTOR.

Interestingly, IGF-II is produced by choroid plexus and released in the cerebrospinal fluid (CSF), allowing it to come in contact with the neurogenic niches. NSCs in the SVZ extend a process through the ventricular wall and come in contact with the CSF directly, thereby allowing its composition to directly alter their regulation. Increased presence of CSF IGF-II during development for example, promotes neurogenesis (Lehtinen et al., 2011; Ziegler et al., 2015). IGF-II is also involved in hippocampal neurogenesis in adulthood (Bracko et al., 2012). In vitro and in vivo studies showed IGF-II involvement in promoting NSC maintenance (Ziegler et al., 2012). Studies have also linked IGF-II dependent mechanisms to hippocampaldependent memory retention (Chen et al., 2011) and more specifically to age-related cognitive decline (Steinmetz et al., 2016) in rodents, further supporting a link between IGF-II and NSCs function and presenting a key target for further researching seeking to preserve AHN during aging (See Table 1). 
The overall effects of this pathway on NSC regulation however, remain inconclusive due to a limited number of concordant studies (Åberg et al., 2003; Itoh et al., 2012); some studies have reported increased IIS resulting in a beneficial increase in adult neurogenesis, for example during GH and IGF-1 mediated increases in neurogenesis as a result of exercise (Berg and Bang, 2004) or following a blueberry supplemented diet in rodents (Shukitt-Hale et al., 2015). In contrast, CR, which is known to directly target and diminish IIS, has also been proven beneficial for both cognition and longevity in rodent models of Alzheimer's disease (Parrella et al., 2013). Figure 2 summarizes some of the NSC functions affected by the IIS pathway. As for mTOR, this highlights the need of a fine-tuned balance between IIS activation and inhibition throughout the lifespan. It is likely that several other factors such as oxidative state of the cell, biological age and brain region all play a role in this balance and can propel toward a positive or negative effect of the IIS pathway.

\section{Sirtuins}

Sirtuins are a group of deacetylases initially shown to extend lifespan in yeast by regulating mitochondrial function and cellular redox state (Aguilaniu et al., 2003). Deacetylases are key regulatory proteins as they can control the expression of several genes. Furthermore, sirtuin activity is NAD-dependent, making them likely candidates for the molecular link between metabolism and aging owing to their ability to respond to the cell's energy status. Indeed, Sir2 activation in yeasts mimics CR-induced longevity, which in turn was shown to depend on the Sirtuin pathway (Lin et al., 2000). Increased lifespan as a result of sirtuin overexpression was also confirmed in other organisms such as Drosophila and C. elegans (Guarente, 2007). Similarly, the mammalian components of the sirtuin family, SIRT1 and SIRT4 have also been implicated in CR diet-regulated processes, showing that the link between metabolism and aging could be conserved across species (Guarente, 2007). Research into Sirtuins also highlighted the importance of NAMPT, the rate limiting enzyme in mammalian $\mathrm{NAD}+$ synthesis; aging is accompanied by chronic DNA damage which leads to NAD+ depletion, Sirt1 inactivation and thus mitochondrial dysfunction (Guarente, 2014). Overexpression of NAMPT can rescue NAD+ levels and counteract these changes as shown by interesting studies investigating its effects on the accelerated aging disorder, Cockanye syndrome (van der Veer et al., 2007; Guarente, 2014; Scheibye-Knudsen et al., 2014). The importance of NAD+ and sirtuins in aging was also supported by recent studies by Song and colleagues showing that NAMPT inhibition is sufficient to induce senescence in human fibroblasts (Song et al., 2015).

The above studies however did not focus on the effects of NAMPT on NSCs. Interestingly, a recent study showed that NAMPT ablation recapitulated aspects of NSC aging such as decreased NSC proliferation in rodents (Stein and Imai, 2014), suggesting that NAMPT and the sirtuin pathway play key roles in NSC aging as well. Studies are now beginning to integrate the role of sirtuins, aging and diet or nutrition on the CNS specifically. For example, increased Sirt1 levels in murine brains due to CR were shown to increase anxiety and decrease exploratory drive (Libert et al., 2011). Whilst NSC function was not assessed in these studies, these conditions are known to involve deregulation of hippocampal neurogenesis (Libert et al., 2011; Hill et al., 2015) making it a plausible underlying mechanism. These studies also highlighted a possible disadvantage of increased Sirtl activity and CR. In line with this, when the effect of SIRT1 deletion was investigated in prion disease, a condition in which neurogenic deregulation is also implicated (Gomez-Nicola et al., 2014), it was found to delay disease onset and to prolong the healthy portion of the affected animals. This was mimicked by CR (Chen et al., 2008). In contrast, others have shown that sirtuins can have neuroprotective functions in response to neuronal damage and neurodegenerative conditions; firstly, SIRT1 is upregulated in mouse models of Alzheimer's disease and amyotrophic lateral sclerosis and shown to enhance neuronal survival both in vitro and in vivo (Kim et al., 2007). Furthermore, SIRT1 was also found responsible for neuroprotective effects in murine models of axonal injury (Araki et al., 2004). SIRT1 overexpression was found to replicate the beneficial effects of CR in the context of several neurodegenerative conditions in various animal models (Gräff et al., 2013).

As many neurodegenerative conditions experience changes in neurogenesis, it is likely Sirt1 conveys some of its effects by influencing NSC function. SIRT1 activation in particular was linked to changes in neurogenesis in the perinatal SVZ; oxidizing conditions were found to activate SIRT1 and push the progenitor pool toward astrocytic differentiation whereas a reducing environment would promote neuronal differentiation (Prozorovski et al., 2008). Similarly, blocking Sirt1 activity disengaged redox changes from SVZ NSC fate (Prozorovski et al., 2008). Rafalski et al. in contrast, showed that Sirt1 inactivation pushed NSCs toward an oligodendrocyte lineage (Rafalski et al., 2013). Following Prozorovski's results, it is possible that the neuroprotective effect of SIRT1 activation, in part, is explained by improved CNS support from an increased number of astrocytes (See Table 1). An interesting avenue would be to investigate whether this finding is replicated in the DG and how this SIRT1mediated modulation of the NSC pool changes with age.

Finally, these findings are now being investigated in human populations, Libert and colleagues for example showed that rare human SIRT1 variants are associated with anxiety and mood disorders (Libert et al., 2011). Interestingly, Sirt1 is also one of the two genes recently implicated in major depressive disorder by whole-genome sequencing findings (Cai et al., 2015). Though dietary interventions such as CR seem to be the most potent effectors of Sirtuin activation, some nutrients, like polyphenols have also been identified to directly activate components of this family (Howitz et al., 2003). Together the studies reported above, suggest the relationship between Sirt1, CR, and aging is regulated by intricate mechanisms, which become even more complex when acting upon different types of NSCs. The key NSC's functions acted upon by the sirtuin pathway are reported in Figure 2.

\section{EPIGENETICS}

Epigenetics is at the forefront of aging research, a position supported by the recent establishment of an "epigenetic clock" by Steve Horvath, and has clear functions in adapting the organism's responses to its environment. These attributes make it a key 
mechanism mediating cellular and molecular responses to diet and aging processes (Rea et al., 2016). Epigenetic modulation comprises many mechanisms and is usually identified as the driving force behind changes in gene expression, which are not due to DNA sequence mutations. Such a process clearly has very important functions in stem cell regulation of different tissues as it can confer lineage-determining decisions as well as maintain quiescence. Epigenetics also plays an important role in aging; twin studies showed that genetic background only has a $25 \%$ influence on longevity (Herskind et al., 1996) suggesting that the remaining effects would be dictated by the environment, which usually ensues its effects through epigenetics. A role for epigenetics is also supported by notion that the effect of genetic variations on cognition and brain structure increases with age, recently reviewed by Papenberg et al. (2015). One of such environmental factors able to cause epigenetic changes is likely to be diet.

A line of thought believes that as epigenetic changes are less permanent, it would be more efficient to target and reverse them rather than targeting any genetic mutations which may arise as a result of aging (Rando and Chang, 2012; Beerman and Rossi, 2015). By restoring a "young" epigenetic environment one may be able to reverse age-related deficit; in a similar manner to the aforementioned heterochronic parabiosis studies (Villeda et al., 2014). Another factor supporting the notion that targeting epigenetics may be an efficient way to reverse aging comes from studies showing that only a small number of loci are altered consistently throughout aging, allowing for targeted interventions rather than global ones (Beerman and Rossi, 2015). Furthermore, epigenetic changes could be used as aging biomarkers, providing important information on the aging rate of an organism, with the potential to enable more precise preventive strategies. It is therefore important for us to understand how age and nutrition affect epigenetics and how this causes alterations in NSC regulation, disease progression and longevity. For the remainder of this section we will evaluate the evidence for such a relationship.

\section{Epigenetics and Nutrition}

There are several studies showing perinatal or in utero nutrition can have vast effect on health later in life, mainly related to cardiovascular disease, diabetes and obesity (Choi and Friso, 2010). Interestingly, these effects were also witnessed in the offspring of the affected animals suggesting that epigenetic changes could be passed through generations. The involvement of epigenetics was also confirmed via methylome analysis, though a causal link is yet to be shown (Radford et al., 2014; Fontana and Partridge, 2015). Such mechanisms are set in place to ensure adaptation for the fetus to its environment-CR and DR prepares a fetus to food scarcity whilst over nutrition primes for a nutrient abundant environment. Studies have suggested it may be the mismatching of predicted and actual nutrient availability to cause some of the detrimental health effects later in life (Perera and Herbstman, 2011).

While epigenetic changes occurring during the malleable stages development in response to nutrition have been extensively studied, those happening during adulthood are less known. The evidence from developmental studies reported above, however shows that mechanisms are set in place for epigenetics to respond to dietary and nutritional cues through the lifespan. Indeed, diet can alter epigenetics in several ways, these include the donation of methyl groups and the regulation of several enzymes (Mathers and Ford, 2009). As well as the alterations in response to $\mathrm{CR}$ and $\mathrm{DR}$, other dietary alterations can have effects on epigenetics, such as the intake of specific nutrients. Studies on agouti mice showed a methyl-supplemented diet was able to cause DNA hypermethylation, making it likely for diet-acquired methyl donors like choline and methionine (an essential amino acid) to have similar effects (Waterland and Jirtle, 2003; Niculescu et al., 2006; Waterland et al., 2007). Furthermore, the trace mineral zinc interacts with histone deacetylase regulation (HDAC) and causes their inhibition (Myzak et al., 2006) whilst resveratrol, a dietary phenol, activates the HDAC SIRT1 (Rafalski and Brunet, 2011). Vitamin D also appears to form an important link between nutrition, aging and epigenetics as its varying concentrations can delay the aging phenotype in mice and its mechanism of action is known to involve histone acetylases (HATs) and HDACs (Tuohimaa, 2009).

\section{Epigenetics, Aging, and Neural Stem Cells}

Several years ago it was found that cellular methyl content declines with increasing age in mammals (Wilson and Jones, 1983). This loss is likely to contribute to genomic instability, which is a hallmark of aging cells. Recently, Horvath and colleagues showed the existence of an epigenetic clock and developed a predictor able to estimate the methylation age of most tissues or cell types, suggesting that specific epigenetic changes occur as a result of age (Horvath, 2013).

Though there are a number of possible epigenetic marks, methylation is the mark considered to be the most stable one and thus the most likely candidate for encoding aging and nutritional changes. Methylation changes as a result of age can be divided into two main categories: those resulting from loss of fidelity when copying methylation marks and those arising from abnormal addition or removal of methylation marks. Further to this, a decrease in the activity and expression of the DNA methyltransferase DNMT1 was found with increasing age (Cooney, 1993). Interestingly, DNMT1 controls stem cell balance and lineage decisions in several tissues; its knock out in embryonic NSCs, for example, causes a preferential push toward astroglial differentiation (Fan et al., 2005). DNMT1 loss in general causes an aging phenotype highlighting it as a key molecule governing aging processes (Beerman and Rossi, 2015). In contrast, some housekeeping genes that are usually unmethylated seem to become methylated with age. This may be due to an increase in DNMT3 activity; DNMT3 is a methyltransferase responsible for de novo methylation, a process shown to be key in regulating stem cells as it halts self-renewal to allow differentiation. A DNMT3 knock out in mouse in fact showed impaired post-natal SVZ and SGL NSC differentiation (Wu et al., 2010) (See Table 1).

An important methylation mark, studied in the field of aging and NSCs, is the methylation of lysine 27 on histone 3 (H3K27). 
The differing methylation of this mark in fact can regulate adult NSC differentiation; when this mark has a single methylation, transcription is enabled, when the mark has 2 or 3 methyl groups gene transcription is repressed (Zhang et al., 2014). Another epigenetic mark often involved in aging is histone acetylation; several histone acetylases (HATs) are key in regulating the NSC pool by affecting both proliferation and differentiation of the neural progenitors. Sirtuins as detailed above are part of this family. There is also evidence of different epigenetic marks influencing one another-i.e., DNA methylation being restricted by acetylation marks (Beerman and Rossi, 2015). See Figure 2 for a representation of this interconnection. Mathers and Ford suggest that changes in methylation do not occur in every cell in a tissue. They explain how this leads to promoter methylation heterogeneity and thus to divergent gene expression and cellular response across different tissues with increasing age (Mathers and Ford, 2009). Together these studies show that epigenetic mechanisms are pivotal to a permissive or restricting environment for gene transcription in response to environmental cues and are therefore likely molecular effectors of nutrient intake and its ensuing effect on NSC regulation.

Finally, as well as sharing common downstream mechanisms, aging and nutrition can also affect one another; for example, nutrient intake may change as a result of age which could then cause the age-related epigenetic changes. A reduction of fruit and vegetable intake for instance, would reduce the intake of zinc and thus affect HDAC function (Mathers and Ford, 2009). Given the prominent role played by NSCs during aging, an exciting avenue would be to explore epigenetic changes in these cells in response to diet.

\section{CONCLUSION}

In conclusion, though much progress has been made in establishing the role played by nutrition in longevity, and on stem cells more broadly, its role in NSCs regulation is still to be elucidated. In this review we have discussed how mTOR/IIS

\section{REFERENCES}

Åberg, M. A., Åberg, N. D., Hedbacker, H., Oscarsson, J., and Eriksson, P. S. (2000). Peripheral infusion of IGF-I selectively induces neurogenesis in the adult rat hippocampus. J. Neurosci. 20, 2896-2903.

Åberg, M. A., Åberg, N. D., Palmer, T. D., Alborn, A.-M., CarlssonSkwirut, C., Bang, P., et al. (2003). IGF-I has a direct proliferative effect in adult hippocampal progenitor cells. Mol. Cell. Neurosci. 24, 23-40. doi: 10.1016/S1044-7431(03)00082-4

Aguilaniu, H., Gustafsson, L., Rigoulet, M., and Nyström, T. (2003). Asymmetric inheritance of oxidatively damaged proteins during cytokinesis. Science 299, 1751-1753. doi: 10.1126/science.1080418

Altman, J., and Das, G. D. (1965). Autoradiographic and histological evidence of postnatal hippocampal neurogenesis in rats. J. Comp. Neurol. 124, 319-335. doi: $10.1002 / \mathrm{cne} .901240303$

Araki, T., Sasaki, Y., and Milbrandt, J. (2004). Increased nuclear NAD biosynthesis and SIRT1 activation prevent axonal degeneration. Science 305, 1010-1013. doi: $10.1126 /$ science.1098014

Arsenijevic, Y., Weiss, S., Schneider, B., and Aebischer, P. (2001). Insulin-like growth factor-I is necessary for neural stem cell proliferation and demonstrates pathway inhibition and sirtuin activation may enhance longevity and CNS function, an effect achieved at least in part, through their impact on NSC function. Importantly, we have described how these responses can be shaped by diet and nutrition.

Whilst the positive impacts of $\mathrm{CR}$ and IF continue to be detailed in model systems, more targeted pharmacological approaches may be beneficial for use in frail and elderly populations. This highlights the need for a more thorough understanding of the molecular pathways involved in these dietary paradigms.

Further to this, much more research into the genetic and epigenetic influences of diet and nutrition is required, to refine populations that potentially stand to gain the most from such interventions. Despite these caveats, there is much excitement in the field as dietary paradigms such as IF are employed in human studies and the ensuing encouraging results with regards to their impact on cognitive performance (Brandhorst et al., 2015; Fontana and Partridge, 2015).

\section{AUTHOR CONTRIBUTIONS}

The co-authors fulfill the criteria for authorship; they all contributed to the manuscript, approved it and agree to be accountable for its content. Cd, TM, and ST conceived the review, $\mathrm{Cd}$ carried out the literature review research, Cd and TM wrote the manuscript, ST revised the manuscript. The manuscript and parts of it, have not been, and will not be submitted elsewhere for publication.

\section{FUNDING}

This review was written in relation to a grant awarded by the Medical Research Council UK (MR/N030087/1) (ST), Cd was supported by the Institute of Psychiatry, Psychology and Neuroscience Ph.D. Prize Studentship Award, TM was supported by the Medical Research Council UK (MR/K500811/1) and the Cohen Charitable Trust. distinct actions of epidermal growth factor and fibroblast growth factor-2. $J$ Neurosci. 21, 7194-7202.

Bartke, A., Sun, L. Y., and Longo, V. (2013). Somatotropic signaling: trade-offs between growth, reproductive development, and longevity. Physiol. Rev. 93, 571-598. doi: 10.1152/physrev.00006.2012

Beerman, I., and Rossi, D. J. (2015). Epigenetic control of stem cell potential during homeostasis, aging, and disease. Cell Stem Cell 16, 613-625. doi: 10.1016/j.stem.2015.05.009

Behrens, A., van Deursen, J. M., Rudolph, K. L., and Schumacher, B. (2014). Impact of genomic damage and ageing on stem cell function. Nat. Cell Biol. 16, 201-207. doi: $10.1038 /$ ncb2928

Berg, U., and Bang, P. (2004). Exercise and circulating insulin-like growth factor I. Horm. Res. 62(Suppl. 1), 50-58. doi: 10.1159/000080759

Bergmann, O., Spalding, K. L., and Frisén, J. (2015). Adult neurogenesis in humans. Cold Spring Harb. Perspect. Biol. 7:a018994. doi: 10.1101/cshperspect. a018994

Blagosklonny, M., V (2008). Aging, stem cells, and mammalian target of rapamycin: a prospect of pharmacologic rejuvenation of aging stem cells. Rejuvenation Res. 11, 801-808. doi: 10.1089/rej.2008. 0722 
Blagosklonny, M. V. (2010). Calorie restriction: decelerating mTOR-driven aging from cells to organisms (including humans). Cell Cycle 9, 683-688. doi: 10.4161/cc.9.4.10766

Blüher, M., Kahn, B. B., and Kahn, C. R. (2003). Extended longevity in mice lacking the insulin receptor in adipose tissue. Science 299, 572-574. doi: 10.1126/science.1078223

Bonafè, M., Barbieri, M., Marchegiani, F., Olivieri, F., Ragno, E., Giampieri, C., et al. (2003). Polymorphic variants of insulin-like growth factor I (IGF-I) receptor and phosphoinositide 3-kinase genes affect IGF-I plasma levels and human longevity: cues for an evolutionarily conserved mechanism of life span control. J. Clin. Endocrinol. Metab. 88, 3299-3304. doi: 10.1210/jc.2002-021810

Bondolfi, L., Ermini, F., Long, J. M., Ingram, D. K., and Jucker, M. (2004). Impact of age and caloric restriction on neurogenesis in the dentate gyrus of C57BL/6 mice. Neurobiol. Aging 25, 333-340. doi: 10.1016/S0197-4580(03)00083-6

Bracko, O., Singer, T., Aigner, S., Knobloch, M., Winner, B., Ray, J., et al. (2012). Gene expression profiling of neural stem cells and their neuronal progeny reveals IGF2 as a regulator of adult hippocampal neurogenesis. J. Neurosci. 32, 3376-3387. doi: 10.1523/JNEUROSCI.4248-11.2012

Brandhorst, S., Choi, I. Y., Wei, M., Cheng, C. W., Sedrakyan, S., Navarrete, G., et al. (2015). A periodic diet that mimics fasting promotes multi-system regeneration, enhanced cognitive performance, and healthspan. Cell Metab. 22, 86-99. doi: 10.1016/j.cmet.2015.05.012

Cai, N., Bigdeli, T. B., Kretzschmar, W., Li, Y., Liang, J., Song, L., et al. (2015). Sparse whole-genome sequencing identifies two loci for major depressive disorder. Nature 523, 588-591. doi: 10.1038/nature14659

Carson, M. J., Behringer, R. R., Brinster, R. L., and McMorris, F. A. (1993). Insulin-like growth factor I increases brain growth and central nervous system myelination in tTransgenic mice. Neuron 10, 729-740. doi: 10.1016/0896-6273(93)90173-O

Castilho, R. M., Squarize, C. H., Chodosh, L. A., Williams, B. O., and Gutkind, J. S. (2009). mTOR mediates Wnt-induced epidermal stem cell exhaustion and aging. Cell Stem Cell 5, 279-289. doi: 10.1016/j.stem.2009. 06.017

Chaker, Z., Aï, S., Berry, H., and Holzenberger, M. (2015). Suppression of IGF-I signals in neural stem cells enhances neurogenesis and olfactory function during aging. Aging Cell 14, 847-856. doi: 10.1111/acel. 12365

Check Hayden, E. (2014). Pet dogs set to test anti-ageing drug. Nature 514, 546. doi: $10.1038 / 514546 a$

Chen, D., Steele, A. D., Hutter, G., Bruno, J., Govindarajan, A., Easlon, E., et al. (2008). The role of calorie restriction and SIRT1 in prion-mediated neurodegeneration. Exp. Gerontol. 43, 1086-1093. doi: 10.1016/j.exger.2008.08.050

Chen, D. Y., Stern, S. A., Garcia-Osta, A., Saunier-Rebori, B., Pollonini, G., Bambah-Mukku, D., et al. (2011). A critical role for IGF-II in memory consolidation and enhancement. Nature 469, 491-497. doi: $10.1038 /$ nature 09667

Chigogora, S., Zaninotto, P., Kivimaki, M., Steptoe, A., and Batty, G. D. (2016). Insulin-like growth factor 1 and risk of depression in older people: the English Longitudinal Study of Ageing. Transl. Psychiatry 6:e898. doi: $10.1038 /$ tp. 2016.167

Choi, S.-W., and Friso, S. (2010). Epigenetics: a new bridge between nutrition and health. Adv. Nutr. 1, 8-16. doi: 10.3945/an.110.1004

Clayton, R. N. (2003). Cardiovascular function in acromegaly. Endocr. Rev. 24, 272-277. doi: 10.1210/er.2003-0009

Conboy, I. M., and Rando, T. A. (2012). Heterochronic parabiosis for the study of the effects of aging on stem cells and their niches. Cell Cycle 11, 2260-2267. doi: 10.4161/cc.20437

Cooney, C. A. (1993). Are somatic cells inherently deficient in methylation metabolism? A proposed mechanism for DNA methylation loss, senescence and aging. Growth. Dev. Aging 57, 261-273.

Cuervo, A. M. (2008). Autophagy and aging: keeping that old broom working. Trends Genet. 24, 604-612. doi: 10.1016/j.tig.2008. 10.002

Day, K., Shefer, G., Shearer, A., and Yablonka-Reuveni, Z. (2010). The depletion of skeletal muscle satellite cells with age is concomitant with reduced capacity of single progenitors to produce reserve progeny. Dev. Biol. 340, 330-343. doi: 10.1016/j.ydbio.2010.01.006
Enwere, E., Shingo, T., Gregg, C., Fujikawa, H., Ohta, S., and Weiss, S. (2004). Aging results in reduced epidermal growth factor receptor signaling, diminished olfactory neurogenesis, and deficits in fine olfactory discrimination. J. Neurosci. 24, 8354-8365. doi: 10.1523/JNEUROSCI.275104.2004

Ernst, A., Alkass, K., Bernard, S., Salehpour, M., Perl, S., Tisdale, J., et al. (2014). Neurogenesis in the striatum of the adult human brain. Cell 156, 1072-1083. doi: 10.1016/j.cell.2014.01.044

Fan, G., Martinowich, K., Chin, M. H., He, F., Fouse, S. D., Hutnick, L., et al. (2005). DNA methylation controls the timing of astrogliogenesis through regulation of JAK-STAT signaling. Development 132, 3345-3356. doi: 10.1242/dev. 01912

Fok, W. C., Chen, Y., Bokov, A., Zhang, Y., Salmon, A. B., Diaz, V., et al. (2014). Mice fed rapamycin have an increase in lifespan associated with major changes in the liver transcriptome. PLoS ONE 9:e83988. doi: 10.1371/journal.pone.0083988

Fontana, L., and Partridge, L. (2015). Promoting health and longevity through diet: from model organisms to humans. Cell 161, 106-118. doi: $10.1016 /$ j.cell.2015.02.020

Fontana, L., Partridge, L., and Longo, V. D. (2010). Extending healthy life spanfrom yeast to humans. Science 328, 321-326. doi: 10.1126/science.1172539

Franklin, N. C., and Tate, C. A. (2008). Lifestyle and successful aging: an overview. Am. J. Lifestyle Med. 3, 6-11. doi: 10.1177/1559827608326125

Gems, D., and de la Guardia, Y. (2013). Alternative perspectives on aging in caenorhabditis elegans: reactive oxygen species or hyperfunction? Antioxid. Redox Signal. 19, 321-329. doi: 10.1089/ars.2012.4840

Gomez-Nicola, D., Suzzi, S., Vargas-Caballero, M., Fransen, N. L., Al-Malki, H., Cebrian-Silla, A., et al. (2014). Temporal dynamics of hippocampal neurogenesis in chronic neurodegeneration. Brain 137, 2312-2328. doi: 10.1093/brain/awu155

Gräff, J., Kahn, M., Samiei, A., Gao, J., Ota, K. T., Rei, D., et al. (2013). A dietary regimen of caloric restriction or pharmacological activation of SIRT1 to delay the onset of neurodegeneration. J. Neurosci. 33, 8951-8960. doi: 10.1523/JNEUROSCI.5657-12.2013

Guarente, L. (2007). Sirtuins in aging and disease. Cold Spring Harb. Symp. Quant. Biol. 72, 483-488. doi: 10.1101/sqb.2007.72.024

Guarente, L. (2014). Linking DNA damage, NAD(+)/SIRT1, and aging. Cell Metab. 20, 706-707. doi: 10.1016/j.cmet.2014.10.015

Han, J., Wang, B., Xiao, Z., Gao, Y., Zhao, Y., Zhang, J., et al. (2008). Mammalian target of rapamycin (mTOR) is involved in the neuronal differentiation of neural progenitors induced by insulin. Mol. Cell. Neurosci. 39, 118-124. doi: $10.1016 /$ j.mcn.2008.06.003

Harrison, D. E., Strong, R., Sharp, Z. D., Nelson, J. F., Astle, C. M., Flurkey, K., et al. (2009). Rapamycin fed late in life extends lifespan in genetically heterogeneous mice. Nature 460, 392-395. doi: 10.1038/nature 08221

Herskind, A. M., McGue, M., Holm, N. V., Sørensen, T. I., Harvald, B., and Vaupel, J. W. (1996). The heritability of human longevity: a population-based study of 2872 Danish twin pairs born 1870-1900. Hum. Genet. 97, 319-323. doi: 10.1007/BF02185763

Hill, A. S., Sahay, A., and Hen, R. (2015). Increasing adult hippocampal neurogenesis is sufficient to reduce anxiety and depression-like behaviors. Neuropsychopharmacology 40, 2368-2378. doi: 10.1038/npp.2015.85

Horvath, S. (2013). DNA methylation age of human tissues and cell types. Genome Biol. 14:R115. doi: 10.1186/gb-2013-14-10-r115

Howitz, K. T., Bitterman, K. J., Cohen, H. Y., Lamming, D. W., Lavu, S., Wood, J. G., et al. (2003). Small molecule activators of sirtuins extend Saccharomyces cerevisiae lifespan. Nature 425, 191-196. doi: 10.1038/nature01960

Ingram, D. K., Weindruch, R., Spangler, E. L., Freeman, J. R., and Walford, R. L. (1987). Dietary restriction benefits learning and motor performance of aged mice. J. Gerontol. 42, 78-81. doi: 10.1093/geronj/42.1.78

Itoh, T., Imano, M., Nishida, S., Tsubaki, M., Mizuguchi, N., Hashimoto, S., et al. (2012). (-)-Epigallocatechin-3-gallate increases the number of neural stem cells around the damaged area after rat traumatic brain injury. J. Neural Transm. 119, 877-890. doi: 10.1007/s00702-011-0764-9

Kalichman, L., Rodrigues, B., Gurvich, D., Israelov, Z., and Spivak, E. (2007). Impact of patient's weight on stroke rehabilitation results. Am. J. Phys. Med. Rehabil. 86, 650-655. doi: 10.1097/PHM.0b013e318115f41b 
Katsimpardi, L., Litterman, N. K., Schein, P. A., Miller, C. M., Loffredo, F. S., Wojtkiewicz, G. R., et al. (2014). Vascular and neurogenic rejuvenation of the aging mouse brain by young systemic factors. Science 344, 630-634. doi: $10.1126 /$ science. 1251141

Keenan, K. P., Smith, P. F., Hertzog, P., Soper, K., Ballam, G. C., and Clark, R. L. (1994). The effects of overfeeding and dietary restriction on Sprague-Dawley rat survival and early pathology biomarkers of aging. Toxicol. Pathol. 22, 300-315. doi: $10.1177 / 019262339402200308$

Kim, D., Nguyen, M. D., Dobbin, M. M., Fischer, A., Sananbenesi, F., Rodgers, J. T., et al. (2007). SIRT1 deacetylase protects against neurodegeneration in models for Alzheimer's disease and amyotrophic lateral sclerosis. EMBO J. 26, 3169-3179. doi: 10.1038/sj.emboj.7601758

Kimura, K. D., Tissenbaum, H. A., Liu, Y., and Ruvkun, G. (1997). daf-2, an insulin receptor-like gene that regulates longevity and diapause in Caenorhabditis elegans. Science 277, 942-946. doi: 10.1126/science.277.5328.942

Kojima, T., Kamei, H., Aizu, T., Arai, Y., Takayama, M., Nakazawa, S., et al. (2004). Association analysis between longevity in the Japanese population and polymorphic variants of genes involved in insulin and insulinlike growth factor 1 signaling pathways. Exp. Gerontol. 39, 1595-1598. doi: 10.1016/j.exger.2004.05.007

Kokoeva, M. V., Yin, H., and Flier, J. S. (2005). Neurogenesis in the hypothalamus of adult mice: potential role in energy balance. Science 310, 679-683. doi: $10.1126 /$ science. 1115360

Kumar, S., Parkash, J., Kataria, H., and Kaur, G. (2009). Interactive effect of excitotoxic injury and dietary restriction on neurogenesis and neurotrophic factors in adult male rat brain. Neurosci. Res. 65, 367-374. doi: 10.1016/j.neures.2009.08.015

Lee, J., Duan, W., Long, J. M., Ingram, D. K., and Mattson, M. P. (2000). Dietary restriction increases the number of newly generated neural cells, and induces BDNF expression, in the dentate gyrus of rats. J. Mol. Neurosci. 15, 99-108. doi: 10.1385/JMN:15:2:99

Lee, J., Seroogy, K. B., and Mattson, M. P. (2002). Dietary restriction enhances neurotrophin expression and neurogenesis in the hippocampus of adult mice. J. Neurochem. 80, 539-547. doi: 10.1046/j.0022-3042.2001. 00747.x

Lehtinen, M. K., Zappaterra, M. W., Chen, X., Yang, Y. J., Hill, A. D., Lun, M., et al. (2011). The cerebrospinal fluid provides a proliferative niche for neural progenitor cells. Neuron 69, 893-905. doi: 10.1016/j.neuron.2011.01.023

Libert, S., Pointer, K., Bell, E. L., Das, A., Cohen, D. E., Asara, J. M., et al. (2011). SIRT1 activates MAO-A in the brain to mediate anxiety and exploratory drive. Cell 147, 1459-1472. doi: 10.1016/j.cell.2011.10.054

Lin, S. J., Defossez, P. A., and Guarente, L. (2000). Requirement of NAD and SIR2 for life-span extension by calorie restriction in Saccharomyces cerevisiae. Science 289, 2126-2128. doi: 10.1126/science.289.5487.2126

Loffredo, F. S., Steinhauser, M. L., Jay, S. M., Gannon, J., Pancoast, J. R., Yalamanchi, P., et al. (2013). Growth differentiation factor 11 is a circulating factor that reverses age-related cardiac hypertrophy. Cell 153, 828-839. doi: 10.1016/j.cell.2013.04.015

López-Otín, C., Blasco, M. A., Partridge, L., Serrano, M., and Kroemer, G. (2013). The hallmarks of aging. Cell 153, 1194-1217. doi: 10.1016/j.cell.2013.05.039

López-Toledano, M. A., and Shelanski, M. L. (2004). Neurogenic effect of betaamyloid peptide in the development of neural stem cells. J. Neurosci. 24, 5439-5444. doi: 10.1523/JNEUROSCI.0974-04.2004

López-Toledano, M. A., and Shelanski, M. L. (2007). Increased neurogenesis in young transgenic mice overexpressing human $\mathrm{APP}(\mathrm{Sw}, \mathrm{Ind})$. J. Alzheimers. Dis. $12,229-240$.

Magri, L., and Galli, R. (2013). mTOR signaling in neural stem cells: from basic biology to disease. Cell. Mol. Life Sci. 70, 2887-2898. doi: $10.1007 / \mathrm{s} 00018-012-1196-\mathrm{x}$

Martínez-Cisuelo, V., Gómez, J., García-Junceda, I., Naudí, A., Cabré, R., MotaMartorell, N., et al. (2016). Rapamycin reverses age-related increases in mitochondrial ROS production at complex I, oxidative stress, accumulation of mtDNA fragments inside nuclear DNA, and lipofuscin level, and increases autophagy, in the liver of middle-aged mice. Exp. Gerontol. 83, 130-138. doi: 10.1016/j.exger.2016.08.002

Maruszak, A., Pilarski, A., Murphy, T., Branch, N., and Thuret, S. (2014). Hippocampal neurogenesis in Alzheimer's disease: is there a role for dietary modulation? J. Alzheimers. Dis. 38, 11-38. doi: 10.3233/JAD-131004
Mathers, J. C., and Ford, D. (2009). "Nutrition, epigenetics, and ageing," in Nutrients and Epigenetics, eds S.-W. Choi and S. Frisio (Boca Raton, FL: CRC Press; Taylor \& Francis Group), 175-196. doi: 10.1201/9781420063561.ch8

Mattson, M. P. (2012). Energy intake and exercise as determinants of brain health and vulnerability to injury and disease. Cell Metab. 16, 706-722. doi: 10.1016/j.cmet.2012.08.012

Mihaylova, M. M., Sabatini, D. M., and Yilmaz, Ö. H. (2014). Dietary and metabolic control of stem cell function in physiology and cancer. Cell Stem Cell 14, 292-305. doi: 10.1016/j.stem.2014.02.008

Murphy, T., and Thuret, S. (2015). The systemic milieu as a mediator of dietary influence on stem cell function during ageing. Ageing Res. Rev. 19, 53-64. doi: 10.1016/j.arr.2014.11.004

Myzak, M. C., Ho, E., and Dashwood, R. H. (2006). Dietary agents as histone deacetylase inhibitors. Mol. Carcinog. 45, 443-446. doi: 10.1002/mc.20224

Nagai, M., Kuriyama, S., Kakizaki, M., Ohmori-Matsuda, K., Sone, T., Hozawa, A., et al. (2012). Impact of obesity, overweight and underweight on life expectancy and lifetime medical expenditures: the Ohsaki Cohort Study. BMJ Open 2:e000940. doi: 10.1136/bmjopen-2012-000940

Niccoli, T., and Partridge, L. (2012). Ageing as a risk factor for disease. Curr. Biol. 22, R741-R752. doi: 10.1016/j.cub.2012.07.024

Niculescu, M. D., Craciunescu, C. N., and Zeisel, S. H. (2006). Dietary choline deficiency alters global and gene-specific DNA methylation in the developing hippocampus of mouse fetal brains. FASEB J. 20, 43-49. doi: 10.1096/fj.05-4707com

O' Neill, C. (2013). PI3-kinase/Akt/mTOR signaling: impaired on/off switches in aging, cognitive decline and Alzheimer's disease. Exp. Gerontol. 48, 647-653. doi: 10.1016/j.exger.2013.02.025

Ochocki, J. D., and Simon, M. C. (2013). Nutrient-sensing pathways and metabolic regulation in stem cells. J. Cell Biol. 203, 23-33. doi: 10.1083/jcb.2013 03110

Paik, J., Ding, Z., Narurkar, R., Ramkissoon, S., Muller, F., Kamoun, W. S., et al. (2009). FoxOs cooperatively regulate diverse pathways governing neural stem cell homeostasis. Cell Stem Cell 5, 540-553. doi: 10.1016/j.stem.2009. 09.013

Paliouras, G., Hamilton, L., Aumont, A., Joppé, S., Barnabé-Heider, F., and Fernandes, K. (2012). Mammalian target of rapamycin signaling is a key regulator of the transit-amplifying progenitor pool in the adult and aging forebrain. J. Neurosci. 32, 15012-15026. doi: 10.1523/JNEUROSCI.2248-12.2012

Papenberg, G., Lindenberger, U., and Bäckman, L. (2015). Aging-related magnification of genetic effects on cognitive and brain integrity. Trends Cogn. Sci. 19, 506-514. doi: 10.1016/j.tics.2015.06.008

Park, D., Yang, Y.-H., Bae, D. K., Lee, S. H., Yang, G., Kyung, J., et al. (2013). Improvement of cognitive function and physical activity of aging mice by human neural stem cells over-expressing choline acetyltransferase. Neurobiol. Aging 34, 2639-2646. doi: 10.1016/j.neurobiolaging.2013. 04.026

Parrella, E., Maxim, T., Maialetti, F., Zhang, L., Wan, J., Wei, M., et al. (2013). Protein restriction cycles reduce IGF-1 and phosphorylated Tau, and improve behavioral performance in an Alzheimer's disease mouse model. Aging Cell 12, 257-268. doi: 10.1111/acel.12049

Pencea, V., Bingaman, K. D., Freedman, L. J., and Luskin, M. B. (2001). Neurogenesis in the subventricular zone and rostral migratory stream of the neonatal and adult primate forebrain. Exp. Neurol. 172, 1-16. doi: $10.1006 /$ exnr.2001.7768

Perera, F., and Herbstman, J. (2011). Prenatal environmental exposures, epigenetics, and disease. Reprod. Toxicol. 31, 363-373. doi: $10.1016 /$ j.reprotox.2010.12.055

Prozorovski, T., Schulze-Topphoff, U., Glumm, R., Baumgart, J., Schröter, F., Ninnemann, O., et al. (2008). Sirtl contributes critically to the redoxdependent fate of neural progenitors. Nat. Cell Biol. 10, 385-394. doi: 10.1038/ ncbl700

Radford, E. J., Ito, M., Shi, H., Corish, J. A., Yamazawa, K., Isganaitis, E., et al. (2014). In utero undernourishment perturbs the adult sperm methylome and intergenerational metabolism. Science 345:1255903. doi: $10.1126 /$ science. 1255903

Rafalski, V. A., and Brunet, A. (2011). Energy metabolism in adult neural stem cell fate. Prog. Neurobiol. 93, 182-203. doi: 10.1016/j.pneurobio.2010.10.007 
Rafalski, V. A., Ho, P. P., Brett, J. O., Ucar, D., Dugas, J. C., Pollina, E. A., et al. (2013). Expansion of oligodendrocyte progenitor cells following SIRT1 inactivation in the adult brain. Nat. Cell Biol. 15, 614-624. doi: 10.1038/ncb2735

Rafalski, V. A., Mancini, E., and Brunet, A. (2012). Energy metabolism and energysensing pathways in mammalian embryonic and adult stem cell fate. J. Cell Sci. 125, 5597-5608. doi: 10.1242/jcs. 114827

Rando, T. A., and Chang, H. Y. (2012). Aging, rejuvenation, and epigenetic reprogramming: resetting the aging clock. Cell 148, 46-57. doi: 10.1016/j.cell.2012.01.003

Rea, I. M., Dellet, M., Mills, K. I., and The ACUME2 Project. (2016). Living long and ageing well: is epigenomics the missing link between nature and nurture? Biogerontology 17, 33-54. doi: 10.1007/s10522-015-9589-5

Reed, M. J., Penn, P. E., Li, Y., Birnbaum, R., Vernon, R. B., Johnson, T. S., et al. (1996). Enhanced cell proliferation and biosynthesis mediate improved wound repair in refed, caloric-restricted mice. Mech. Ageing Dev. 89, 21-43. doi: 10.1016/0047-6374(96)01737-X

Renault, V. M., Rafalski, V. A., Morgan, A. A., Salih, D. A. M., Brett, J. O., Webb, A. E., et al. (2009). FoxO3 regulates neural stem cell homeostasis. Cell Stem Cell 5, 527-539. doi: 10.1016/j.stem.2009.09.014

Romine, J., Gao, X., Xu, X.-M., So, K. F., and Chen, J. (2015). The proliferation of amplifying neural progenitor cells is impaired in the aging brain and restored by the mTOR pathway activation. Neurobiol. Aging 36, 1716-1726. doi: 10.1016/j.neurobiolaging.2015.01.003

Sato, A., Sunayama, J., Matsuda, K., Tachibana, K., Sakurada, K., Tomiyama, A., et al. (2010). Regulation of neural stem/progenitor cell maintenance by PI3K and mTOR. Neurosci. Lett. 470, 115-120. doi: 10.1016/j.neulet.2009.12.067

Scheibye-Knudsen, M., Mitchell, S. J., Fang, E. F., Iyama, T., Ward, T., Wang, J., et al. (2014). A high-fat diet and $\mathrm{NAD}(+)$ activate Sirtl to rescue premature aging in cockayne syndrome. Cell Metab. 20, 840-855. doi: 10.1016/j.cmet.2014.10.005

Shukitt-Hale, B., Bielinski, D. F., Lau, F. C., Willis, L. M., Carey, A. N., Joseph, J. A., et al. (2015). The beneficial effects of berries on cognition, motor behaviour and neuronal function in ageing. Br. J. Nutr. 114, 1542-1549. doi: 10.1017/S0007114515003451

Signer, R. A. J., and Morrison, S. J. (2013). Mechanisms that regulate stem cell aging and life span. Cell Stem Cell 12, 152-165. doi: 10.1016/j.stem.2013. 01.001

Solon-Biet, S. M., McMahon, A. C., Ballard, J. W. O., Ruohonen, K., Wu, L. E., Cogger, V. C., et al. (2014). The ratio of macronutrients, not caloric intake, dictates cardiometabolic health, aging, and longevity in ad libitum-fed mice. Cell Metab. 19, 418-430. doi: 10.1016/j.cmet.2014.02.009

Solon-Biet, S. M., Mitchell, S. J., Coogan, S. C. P., Cogger, V. C., Gokarn, R., McMahon, A. C., et al. (2015). Dietary protein to carbohydrate ratio and caloric restriction: comparing metabolic outcomes in mice. Cell Rep. 11, 1529-1534. doi: 10.1016/j.celrep.2015.05.007

Song, T.-Y., Yeh, S.-L., Hu, M.-L., Chen, M.-Y., and Yang, N.-C. (2015). A Nampt inhibitor FK866 mimics vitamin B3 deficiency by causing senescence of human fibroblastic Hs68 cells via attenuation of NAD(+)-SIRT1 signaling. Biogerontology 16, 789-800. doi: 10.1007/s10522-015-9605-9

Spalding, K. L., Bergmann, O., Alkass, K., Bernard, S., Salehpour, M., Huttner, H. B., et al. (2013). Dynamics of hippocampal neurogenesis in adult humans. Cell 153, 1219-1227. doi: 10.1016/j.cell.2013.05.002

Stangl, D., and Thuret, S. (2009). Impact of diet on adult hippocampal neurogenesis. Genes Nutr. 4, 271-282. doi: 10.1007/s12263-009-0134-5

Stein, L. R., and Imai, S. (2014). Specific ablation of Nampt in adult neural stem cells recapitulates their functional defects during aging. EMBO J. 33, 1321-1340. doi: 10.1002/embj.201386917

Steinmetz, A. B., Johnson, S. A., Iannitelli, D. E., Pollonini, G., and Alberini, C. M. (2016). Insulin-like growth factor 2 rescues aging-related memory loss in rats. Neurobiol. Aging 44, 9-21. doi: 10.1016/j.neurobiolaging.2016. 04.006

Suh, Y., Atzmon, G., Cho, M.-O., Hwang, D., Liu, B., Leahy, D. J., et al. (2008). Functionally significant insulin-like growth factor I receptor mutations in centenarians. Proc. Natl. Acad. Sci. U.S.A. 105, 3438-3442. doi: 10.1073/pnas.0705467105

Taguchi, A., Wartschow, L. M., and White, M. F. (2007). Brain IRS2 signaling coordinates life span and nutrient homeostasis. Science 317, 369-372. doi: $10.1126 /$ science. 1142179
Tan, P., Wang, Y.-J., Li, S., Wang, Y., He, J.-Y., Chen, Y.-Y., et al. (2016). The PI3K/Akt/mTOR pathway regulates the replicative senescence of human VSMCs. Mol. Cell. Biochem. 422, 1-10. doi: 10.1007/s11010-0162796-9

Teumer, A., Qi, Q., Nethander, M., Aschard, H., Bandinelli, S., Beekman, M., et al. (2016). Genomewide meta-analysis identifies loci associated with IGF-I and IGFBP-3 levels with impact on age-related traits. Aging Cell 15, 811-824. doi: 10.1111/acel.12490

Tuohimaa, P. (2009). Vitamin D and aging. J. Steroid Biochem. Mol. Biol. 114, 78-84. doi: 10.1016/j.jsbmb.2008.12.020

van der Spoel, E., Jansen, S. W., Akintola, A. A., Ballieux, B. E., Cobbaert, C. M., Slagboom, P. E., et al. (2016). Growth hormone secretion is diminished and tightly controlled in humans enriched for familial longevity. Aging Cell 15, 1126-1131. doi: 10.1111/acel.12519

van der Veer, E., Ho, C., O’Neil, C., Barbosa, N., Scott, R., Cregan, S. P., et al. (2007). Extension of human cell lifespan by nicotinamide phosphoribosyltransferase. J. Biol. Chem. 282, 10841-10845. doi: 10.1074/jbc.C700018200

van Heemst, D. (2010). Insulin, IGF-1 and longevity. Aging Dis. 1, 147-157.

Verburgh, K. (2015). Nutrigerontology: why we need a new scientific discipline to develop diets and guidelines to reduce the risk of aging-related diseases. Aging Cell 14, 17-24. doi: 10.1111/acel.12284

Villeda, S. A., Luo, J., Mosher, K. I., Zou, B., Britschgi, M., Bieri, G., et al. (2011). The ageing systemic milieu negatively regulates neurogenesis and cognitive function. Nature 477, 90-94. doi: 10.1038/nature 10357

Villeda, S. A., Plambeck, K. E., Middeldorp, J., Castellano, J. M., Mosher, K. I., Luo, J., et al. (2014). Young blood reverses age-related impairments in cognitive function and synaptic plasticity in mice. Nat. Med. 20, 659-663. doi: $10.1038 / \mathrm{nm} .3569$

Wanke, V., Cameroni, E., Uotila, A., Piccolis, M., Urban, J., Loewith, R., et al. (2008). Caffeine extends yeast lifespan by targeting TORC1. Mol. Microbiol. 69, 277-285. doi: 10.1111/j.1365-2958.2008.06292.x

Warr, M. R., Binnewies, M., Flach, J., Reynaud, D., Garg, T., Malhotra, R., et al. (2013). FOXO3A directs a protective autophagy program in haematopoietic stem cells. Nature 494, 323-327. doi: 10.1038/nature 11895

Waterland, R. A., and Jirtle, R. L. (2003). Transposable elements: targets for early nutritional effects on epigenetic gene regulation. Mol. Cell. Biol. 23, 5293-5300. doi: 10.1128/MCB.23.15.5293-5300.2003

Waterland, R. A., Travisano, M., and Tahiliani, K. G. (2007). Diet-induced hypermethylation at agouti viable yellow is not inherited transgenerationally through the female. FASEB J. 21, 3380-3385. doi: 10.1096/fj.07$8229 \mathrm{com}$

Wilson, V., and Jones, P. (1983). DNA methylation decreases in aging but not in immortal cells. Science 220, 1055-1057. doi: 10.1126/science.6844925

Winner, B., Kohl, Z., and Gage, F. H. (2011). Neurodegenerative disease and adult neurogenesis. Eur. J. Neurosci. 33, 1139-1151. doi: 10.1111/j.1460-9568.2011.07613.x

Witte, A. V., Fobker, M., Gellner, R., Knecht, S., and Flöel, A. (2009). Caloric restriction improves memory in elderly humans. Proc. Natl. Acad. Sci. U.S.A. 106, 1255-1260. doi: 10.1073/pnas.0808587106

Wu, H., Coskun, V., Tao, J., Xie, W., Ge, W., Yoshikawa, K., et al. (2010) Dnmt3a-dependent nonpromoter DNA methylation facilitates transcription of neurogenic genes. Science 329, 444-448. doi: 10.1126/science.11 90485

Yang, T.-T., Lo, C.-P., Tsai, P.-S., Wu, S.-Y., Wang, T.-F., Chen, Y.-W., et al. (2015). Aging and exercise affect hippocampal neurogenesis via different mechanisms. PLoS ONE 10:e0132152. doi: 10.1371/journal.pone. 0132152

Ye, P., Li, L., Richards, R. G., DiAugustine, R. P., and D'Ercole, A. J. (2002). Myelination is altered in insulin-like growth factor-I null mutant mice. J. Neurosci. 22, 6041-6051.

Yu, S.-W., Baek, S.-H., Brennan, R. T., Bradley, C. J., Park, S. K., Lee, Y. S., et al. (2008). Autophagic death of adult hippocampal neural stem cells following insulin withdrawal. Stem Cells 26, 2602-2610. doi: 10.1634/stemcells. 2008-0153

Yuan, R., Tsaih, S.-W., Petkova, S. B., Marin de Evsikova, C., Xing, S., Marion, M. A., et al. (2009). Aging in inbred strains of mice: study design and interim 
report on median lifespans and circulating IGF1 levels. Aging Cell 8, 277-287. doi: 10.1111/j.1474-9726.2009.00478.x

Zhang, J., Ji, F., Liu, Y., Lei, X., Li, H., Ji, G., et al. (2014). Ezh2 regulates adult hippocampal neurogenesis and memory. J. Neurosci. 34, 5184-5199. doi: 10.1523/JNEUROSCI.4129-13.2014

Ziegler, A. N., Levison, S. W., and Wood, T. L. (2015). Insulin and IGF receptor signalling in neural-stem-cell homeostasis. Nat. Rev. Endocrinol. 11, 161-170. doi: 10.1038/nrendo.2014.208

Ziegler, A. N., Schneider, J. S., Qin, M., Tyler, W. A., Pintar, J. E., Fraidenraich, D., et al. (2012). IGF-II promotes stemness of neural restricted precursors. Stem Cells 30, 1265-1276. doi: 10.1002/stem.1095
Conflict of Interest Statement: The authors declare that the research was conducted in the absence of any commercial or financial relationships that could be construed as a potential conflict of interest.

Copyright (c) 2017 de Lucia, Murphy and Thuret. This is an open-access article distributed under the terms of the Creative Commons Attribution License (CC $B Y)$. The use, distribution or reproduction in other forums is permitted, provided the original author(s) or licensor are credited and that the original publication in this journal is cited, in accordance with accepted academic practice. No use, distribution or reproduction is permitted which does not comply with these terms. 